\title{
Decision-Making Practices among Air Traffic Controllers during Conflict Resolution in Aviation Industry: A Case Study
}

\author{
Sherrie Winer Anthony* \& Rusli Ahmad \\ Faculty of Cognitive Sciences and Human Development, \\ Universiti Malaysia Sarawak, 94300 Kota Samarahan, Sarawak, Malaysia
}

\begin{abstract}
The study explores decision-making practices among Air Traffic Controllers (ATCOs) in the Civil Aviation Authority of Malaysia (CAAM) in Sarawak, Malaysia, using the Cynefin Framework. The study intends to identify related factors that influence decision-making practices, explore how decisions are made during conflict resolution, and describe the coping strategies in decision-making practices by ATCOs. The qualitative phenomenology case study method was used to collect data and one-to-one interviews with the ATCOs. Content analysis is used to analyse the data. The findings showed that ATCOs types and working experiences influence the way they make decisions. Decision-making among ATCOs is like the Administrative Model in which they must follow Standard Operating Procedures (SOP) as their strategies in decision-making. Findings contribute toward an understanding of current decision-making practices, which would inform relevant policies and professional training development programmes.
\end{abstract}

Keywords: decision-making, air traffic controllers, conflict resolution, aviation industry

ARTICLE INFO

Email address: 21010043@siswa.unimas.my (Sherrie Winer)

*Corresponding author

https://doi.org/10.33736/jcshd.3426.2021

e-ISSN: 2550-1623

Manuscript received: 7 June 2021; Accepted: 27 July 2021; Date of publication: 25 September 2021.

Copyright: This is an open-access article distributed under the terms of the CC-BY-NC-SA (Creative Commons Attribution-NonCommercial-ShareAlike 4.0 International License), which permits unrestricted use, distribution, and reproduction in any medium, for non-commercial purposes, provided the original work of the author(s) is properly cited. 


\section{INTRODUCTION}

Decision-making is an act of determining a choice among two or more alternatives (Robbins \& Coulter, 2014). Decision-making among Air Traffic Controllers (ATCOs) during conflict resolution must be appropriately managed to ensure safety. As decision made by ATCOs involves safety aspect of the aircraft and human, they need to make sure that the decision is quick and correct. In their scope of work and responsibility, ATCOs must decide in a noticeably brief time to solve any conflict that occurs. If there is a delay in decision-making, an accident such as an aircraft crash may happen. Akrani (2011) synonymously claimed that a fast and right decision would lead to a problem being solved. For example, when there is an emergency in which an aircraft need to reroute to avoid collision with other aircraft, ATCOs need to quickly inform the ATCOs and pilots in the aircraft to change their route.

Empirically, there was quantitative research conducted by E and Zhang (2017) in China to study the influence of thinking style on decision-making intervention among ATCOs. The findings showed that ATCOs who have a holistic thinking style would intervene more and earlier. It results in safer airspace but poor efficiency of airspace control. Other than that, research that was conducted in the United States (US) by Bonaceto, Estes, Moertl and Burns (2005) explored naturalistic decision-making in the air traffic control tower by highlighting complementary methods. Their methods include Cognitive Analysis and Modeling, Critical Incident Analysis, and Controller Coordination Analysis. These methods are used to evaluate human performance issues. In addition, D'Arcy and Rocco (2001) studied the perspectives of Air Traffic Control Specialists regarding decision-making and planning and related cognitive processes such as learning, memory, and situation awareness in New Jersey. Their qualitative research found that the Air Traffic Control Specialists are putting safety, situation awareness, planning skills, backup strategies, and the collective nature of their task as their priority.

Furthermore, another related research emerged. A study by Aygün, Y1lmaz and Gülseçen (2017) investigated how the value of decision-making for airlines relate to preferences of passengers during check-ins. The quantitative research was carried out in Turkey, and the focus of the research was on decision-making but based on the passengers' preferences during check-ins. There was related research conducted in Malaysia by Anding and Songan (2000). Their qualitative study used cognitive goals to model cognitive tasks in air traffic control, and they discovered that cognitive goals helped develop cognitive models in task analysis. Plus, the findings also suggested implementing appropriate tasks to systematically design a training program in air traffic control. Another related research in Malaysia was conducted by Sidik, Rahman and Mohamed (2017), which evaluated the strategies applied by ATCOs during Procedural Control. Their findings emphasized the most critical issue, which was on delays.

Cognitive Task Analysis (CTA) has been the focus in most previous studies about air traffic control. As explained by Clark, Feldon, Merriënboer, Yates and Early (2007), CTA is one of the approaches to explain knowledge needed for a particular performance. Clark et al. (2007) discussed CTA in research and practice, which involve various interviews and observation approaches in performing complex tasks. They found out that CTA contributed to instructional technology due to the "cognitive revolution" in psychology and education since the 1970s. Most 
of these studies were conducted overseas. The lack of inquiry within the Malaysian context points to a gap in research.

The aviation industry was shaken by the unfortunate crash of Malaysia Airlines Flight 17 (MH17) on 17 July 2014 in eastern Ukraine, and how quickly it was referred to as a worldwide tragedy (Lewis, 2014). It was the second incident after flight MH 370 on 8 March in the same year. Clem (2017) reported that the fateful aircraft had followed standard civil aviation flight routes and at the same time was under continuous air traffic control. However, there was an issue regarding air-toground transmission tapes between the air traffic controller of Ukraine and MH17 (Hussain \& Lokman, 2014). These cases showed how decisions were crucial in the aviation industry as they dealt with the safety of human life.

To understand the process of decision-making in the aviation industry, this study intends to use the Cynefin framework by Snowden and Boone (2007) in exploring the decision-making practices by ATCOs. The framework consists of five contexts (simple, complicated, complex, chaotic and disorder) that assist leaders to identify the prevailing operative context to make the right decision. In this study, we attempt to identify which context ATCOs would use while deciding on conflict resolutions. Therefore, the study intends to explore decision-making styles among ATCOs in the Malaysian aviation industry. Several research questions need to be asked, such as the roles of ATCOs and coping strategies applied by ATCOs in making decisions during critical situations.

\section{BACKGROUND OF STUDY}

Decision-Making Process involves several phases. Robbins and Coulter (2014) stated that the decision-making process involves stages: identify a problem, identify decision criteria, allocate weights to the criteria, develop alternatives, analyse alternatives, select an alternative, implement the alternative, and evaluate decision effectiveness. In connection with that, Verma (2014) conducted research to study different Decision-Making Models, including rational models, normative models, administrative models, political models, and ethical models. The Ethical Decision-Making Model is the most influential model, according to Verma (2014), because ethics in business are the crucial matter within the entire organisation. Every organisation should set up their ethics code to have transparency, especially regarding financial aspects. Simon (1994) mentioned intelligence, design, and choice activities (Marume, Ndudzo \& Chikasha, 2016). Intelligence activity is the phase in which an individual searches for reasons to make a decision. The next stage, design activity, is searching for alternatives action courses, which involves creating, establishing and examining possible action courses. The last stage is a Choice activity which requires choosing an action course based on the given alternatives.

As Khakheli and Morchiladze (2015) discussed, factors influencing decision-making include knowledge, manager's experience, and the possibility of understanding the process and objective factors. A knowledgeable manager will make better decisions for the organisation. People learn from experience. Thus, individual who has more experience will have the possibility to make a wise decision. Decision-makers need to understand the problem to choose the right decision by considering all the related factors. 
Apart from that, D'Arcy and Rocco (2001) reported that the factors affecting decision-making among Air Traffic Control Specialists (ATCOs) include decision-maker related factors, taskrelated factors, and contextual factors. The first factor focuses more on how novices and experts make the decision. An expert performs better by making decisions. Meanwhile, a novice can make a decision too, especially for routine tasks but by applying automated aids. On the other hand, taskrelated factors include the complexity of the controller's sector, volume and complexity of the traffic, and time pressures. Controllers responsible for making the decision as an area controller might face varied factors than controllers working as aerodrome controllers. Finally, contextual factors such as among controllers, management leadership types and pilots' requests also affect decision-making made by the controllers. Controllers will generate better decisions when they have a good collaboration with each other, including the pilots.

According to Kudryavtsev and Pavlodsky (2012), there are two categories of decision tasks which are description-based and experience-based. Description-based decisions are decisions made by referring to statistical descriptions. Meanwhile, experience-based decisions are decisions made by using past personal experience. Decision-makers who use description-based decisions decide by depending on any descriptions available such as deciding the best place to organise a workshop by referring to information available in brochures. In experienced-based decisions, decision-makers decide and get the opportunity to learn based on the decision made. In the future, they might make the same decision as in the past if the decision works well with their current situation. Thus, the decision gets repeated.

Collaborative Decision Making is when the opinions from some stakeholders are crucial for the decision to be made (Zaraté, Konate \& Camilleri, 2013). There are two types of cooperation which are Human-System cooperation and Mediated Human-Human cooperation. The first type of cooperation involves coordination between humans as well as systems. As Zaraté, Konate and Camilleri (2013) stated, the system acts as a cooperative role. The system requires actions from a human who plays a user's role before responding as expected by a human. On the other hand, Mediated Human-Human cooperation shall be considered in a group decision-making condition though the system can still be applied. The system in this type of cooperation acts as a facilitator or mediator to ensure mediated Human-Human cooperation.

Aircraft pilots are using aeronautical decision-making (Li, 2011). As cited in Li (2011), Federal Aviation Industry defined aeronautical decision-making as a systematic technique to the mental process utilised by the pilots to identify the best action course to respond towards a condition. Ball, Chen, Hoffman and Vossen (2000) reported that Collaborative Decision Making (CDM) had been implemented in United States (US) that brings a new philosophy to manage air traffic. The pilot and air traffic controllers share the responsibility of ensuring aircraft safety with the involvement of technology. There are two objectives of CDM, as mentioned by Ball et al. (2000). First, CDM is to produce better information. This information refers to the combination of flight data directly by the Airspace System and information from airspace users. In addition, CDM aimed to disseminate the same information for managers of air traffic and airspace users. It also enables direct response from airspace users and collaboration of airspace users and air traffic flow managers. 


\subsection{Conflict Resolution among Air Traffic Controllers}

Conflict resolution faced by ATCOs is the most critical decision involved in the decision-making process. They make decisions regarding ways to keep separation standards between aircraft (Neal, 2008). Erzberger (2014) discussed a conflict resolution algorithm that can give automated separation assurance for the next generation of systems for air traffic control. This algorithm helps reduce the workload of ATCOs as the information is being sent directly to the pilots without having approval from the ATCOs.

\subsection{Cynefin Framework}

The Cynefin framework is a framework of leaders approaching decision-making, as Snowden and Boone (2007) discussed. This framework consists of five contexts, which are defined by the nature of the relationship between cause and effect: simple, complicated, complex, chaotic and disorder. Snowden and Boone (2007) further explained each context. Leaders may quickly identify the right decision in a simple context as it has a clear cause-and-effect relationship. Complicated context is like simple context. There is a clear cause-and-effect relationship; however, it is not as easy as identifying it in a simple context. On the other hand, in a complex context, leaders must probe the problem first and let it emerge before taking action to overcome it. The case is like a chaotic context. In a chaotic context, leaders should search for what works in that situation and quickly come out with a decision. Finally, disorder context is quite hard to identify when leaders are in this situation. Therefore, leaders should separate the situation and classify it into four contexts (simple, complicated, complex, or chaotic).

\section{METHODOLOGY}

The research onion model proposed by Saunders, Lewis, and Thornhill (2019) has been used to guide the structure of the study. The present study employs the interpretivism research philosophy and uses a deductive approach to construct its inquiry. A case study approach is used, and crosssectional data were collected. The case study allows for a focused investigation on a particular issue in a certain period (Yin, 2014). This present study uses a cross-sectional period to collect data by using one-to-one in-depth interviews. The primary data was collected using semistructured interviews using a set of interview protocols identified with all related informants. Focus group discussion was used for data collection. Participants for the focus group discussion are seven ATCOs. Five of the informants had at least 11 years of working experience in the aviation industry; meanwhile, two had 6 to 10 years of working experience. A schedule of interviews and a set of interview scripts were prepared. Validity in research is critical. We focused on internal validity and construct validity to ensure the questions are in line with the current literature and purpose of the inquiry.

Ethics is important in conducting any research. In this study, we protect the privacy of all participants, and data is keep anonymised during analysis and reporting. An informed consent form was used to mandate the permission sought from the participants. 
Content analysis was used to analyse the data. All transcribed data were categorised. Themes were created based on current literature and the issues which emerged during the interviews.

\section{FINDINGS AND DISCUSSION}

The findings and discussion are represented in a "tree diagram" according to research objectives. To answer the first research question, which was to identify related factors that influence decisionmaking practices among ATCOs during conflict resolution, these were the responses collected:

"...for (the) area, related factors considered by ATCOs are weather (including the turbulence of aircraft in the air), prohibited/ danger/ restricted airspace"

- Informant 1

"...equipment which includes ATC equipment and pilot equipment (onboard equipment), weather (good or severe weather such as heavy rain) during day and night, aircraft performance, emergency..."

- Informant 2

"...for approach, whether aircraft is from the same direction traffic, the time factor, aircraft performance, situation (emergency and abnormal situation) ...ATCOs experiences also influencing the way we make decision...."

\section{Informant 3}

"...for (the) tower, aircraft performance, weather, wind factor, (the) configuration of the area, emergency, aircraft performance, emergency..."

- Informant 4

“...safety always comes first, aircraft performance, emergency ...” $\quad$ - Informant 5

"...need to be calm when making (a) decision, aircraft performance, emergency ... - Informant 6

"...to reduce (the) delay of the aircraft, aircraft performance, emergency ..." - Informant 7

These narratives illustrate two main factors that influence decision-making practices among ATCOs during conflict resolution from the perspective of ATCOs types - aircraft performance and emergency. Informant 1 mentioned that aircraft performance and emergencies are applicable for all ATCOs. Aircraft performance is referring to the size of the aircraft and types of aircraft. This factor influences decision-making by ATCOs. For example, they must consider the size and types of aircraft before deciding which aircraft to take off first. The emergency also influences the decision-making of ATCOs as they must think fast and take quick action. For example, they must immediately acknowledge distress (urgency call) when an emergency occurs. Apart from that, decision-making among ATCOs is also influenced by their working period. The working period represents the working experiences of the ATCOs in decision-making during conflict resolution in the aviation industry. Informant 3 added that ATCOs experiences are one of the factors which influence their decision-making process. All informants agreed with his statement. 
As shown in Figure 1 below, two major related factors that influence ATCOs to make decisions during conflict resolution are the ATCOs' task types and their work periods. These findings were consistent with findings by D'Arcy and Rocco (2001). One of the factors considered in the research was task-related factors. Different ATCOs would view several factors based on their types (area controllers, approach controllers and aerodrome controllers). ATCOs who are working as area controllers face different situations from ATCOs working as tower controllers. Based on the findings in Figure 1, their individual working experiences also affect decision-making practices among ATCOs. It is known as experienced-based, as stated by Kudryavtsev and Pavlodsky (2012). ATCOs who have been working for more than eleven years will have more experience in decisionmaking during conflict resolution in the aviation industry.

To conclude, related factors affecting ATCOs are different for area, approach, and aerodrome in deciding and vary based on their working period. According to Kudryavtsev and Pavlodsky (2012), experienced-based decisions refer to decisions made depending on the individuals' previous experiences on related matters. ATCOs will improve their decision-making skills from time to time as they gain experience in performing their daily tasks. For example, it will be easier for ATCOs who have been working for more than eleven years to confront the conflict between two aircraft that need to depart simultaneously. The decision-making process becomes more accessible as they have gained much experience in dealing with such situations. Figure 1 shows related findings for this research objective.

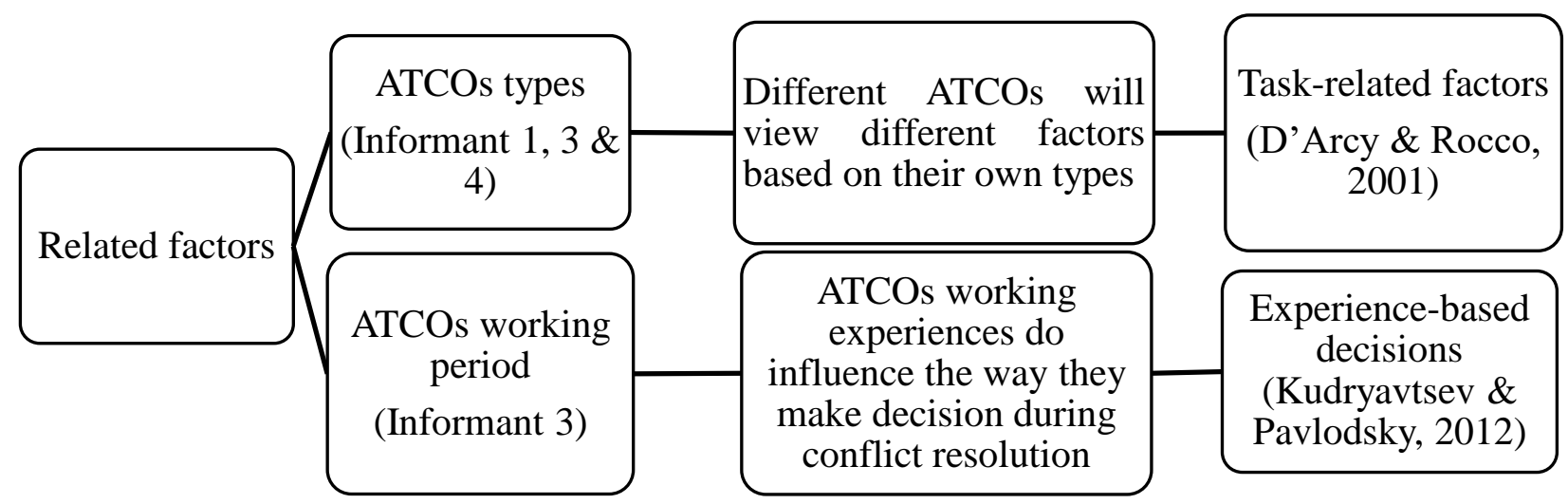

Figure 1. Factors that Influence Decision-Making Practices among ATCOs during Conflict Resolution

\subsection{To explore how ATCOs decide on conflict resolution of the aviation industry}

The following are quotations from the participants: 
"...based on published separation standards...lateral standard, longitudinal standard, vertical standard and wake turbulence standard......decide individually with cooperation, we help each other..."

- Informant 1

"...published separation standard as our guidance material..."

- Informant 2

"...based on published official standards which consist of lateral standard, longitudinal standard, vertical standard ... "...decide individually but at the same time working as a team..."

- Informant 3

“...for tower, we have wake turbulence separation (because we need to avoid the wake turbulence between small and big aircraft - involve time and distance) ...."

- Informant 4

“...we must follow the procedures strictly,...we have the reference book...our teamwork, because when we work, few of us together...."

- Informant 5

"...those duty controllers, she or he has the responsibility to decide, according to the procedures...help each other because not everyone thinks the same thing..."

- Informant 6

"...we have our own manual to follow...we have to think fast and decide on the spot..."

- Informant 7

In short, the main practice of decision-making by ATCOs during conflict resolution of (the) aviation industry is to follow the published official separation standards. The standards consist of lateral standard, longitudinal standard, vertical standard, and wake turbulence standard. In addition, interaction among each other is very crucial in decision making. It is proven by the informants who mentioned helping each other and working as a team.

As shown in Figure 2 below, one of the ways ATCOs make a decision is by referring to the separation standards. General Rules published by the Department of Civil Aviation Malaysia (1999) highlighted the guidelines for ATCOs to decide. According to the Department of Civil Aviation Malaysia (1999), separation for area control depends on estimated and actual times over position reporting points, reports of the visual sighting, radar identification and distance reports. Decision-making by ATCOs during conflict resolution is done by helping each other and working as a team. It is termed Mediated Human-Human Cooperation under group decision-making conditions (Zaraté, Konate, \& Camilleri, 2013). This type of cooperation should enable a new form of interaction to exist among the participants. ATCOs have their responsibility to make decisions and to communicate the decision made for other ATCOs to take appropriate action. The findings of this research are different from the findings of the research conducted by Anding and Songan (2000). The findings from that research were focusing on modelling the cognitive tasks. They identified two main tasks: managing aircraft arrival and departure. 
To conclude, separation standards act as a guideline for ATCOs to decide during conflict resolution to prevent any incident from happening. Cooperation between ATCOs is extremely critical because they need to communicate the decision made by them. Mediated Human-Human Cooperation is one of the types of cooperation in Collaborative Decision Making as stated by Zaraté, Konate, and Camilleri (2013). It involves a few decision-makers at one time. Such type of cooperation is related to the findings. In sum, ATCOs should be allowed to coordinate and communicate with each other. For example, three ATCOs could work together in one area at the same time. One of the ATCOs would need to communicate with an aircraft, another ATCOs would need to communicate with the other aircraft, and the third ATCOs would need to communicate with other ATCOs positioned in other units. Figure 2 shows related findings which respond to the second research question.

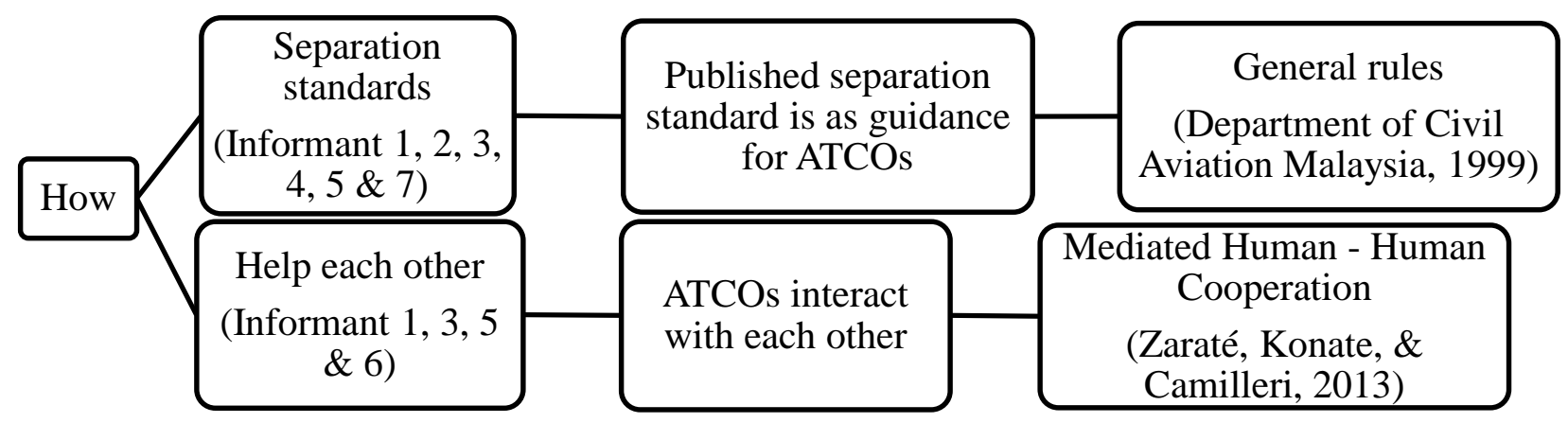

Figure 2. How ATCOS Make Decision during Conflict Resolution of Aviation Industry

\subsection{To describe the coping strategies by ATCOs in deciding on conflict resolution}

The following are quotations from the participants:

“...basic quick reference... flow for aircraft emergency...”

“...we have standard procedures..."

“...for emergency part, normally we have quick reference..."

“...we have step by step procedures for emergency..."

“...we have contingency plans, checklist..."

“...we have contingency plans ...”
- Informant 1

- Informant 2

- Informant 3

- Informant 4

- Informant 5

- Informant 7 
In short, according to Informant 2, the primary coping strategy among ATCOs in decision-making during conflict resolution is to refer to their standard procedures (as supported by Informant 2). On the other hand, (Informant 1, 3, 4, 5 and 7) agree that the primary coping strategy by ATCOs in decision-making during conflict resolution is by having contingency plans.

As shown in Figure 3 below, two main coping strategies by ATCOs for decision-making in conflict resolution are Standard Operating Procedures (SOP) and contingency plans. ATCOs are required to follow the SOP published in their decision-making. It is supported by one of the decisionmaking models, the Administrative Model (Verma, 2014). According to this Model, SOPs are the rules and regulations managers take in solving a problem in a brief time from elementary level. In addition, ATCOs have their contingency plans as one of their strategies in decision-making. According to the Department of Civil Aviation Malaysia (2016), ATCOs have ATC contingencies, including radio communication contingencies. ATCOs must decide in a noticeably brief time. Thus, the decision-making context among ATCOs during conflict resolution is like the chaotic context in Cynefin Framework (Snowden \& Boone, 2007). In a chaotic context, the leaders or decision-makers should search for what works in that situation and quickly decide.

To conclude, two main coping strategies among ATCOs in decision-making during conflict resolution of the aviation industry are to refer to the standard procedures and contingency plans. As Verma (2014) mentioned, the Administrative Model is much related to the coping strategies among ATCOs. It is because decision-makers in this model would have to make the best decision in the least available time. ATCOs, as decision-makers, would need to make a decision quickly to avoid any aircraft collision or accidents which may cause flight delays or mishaps. Figure 3 shows related findings for this research objective.

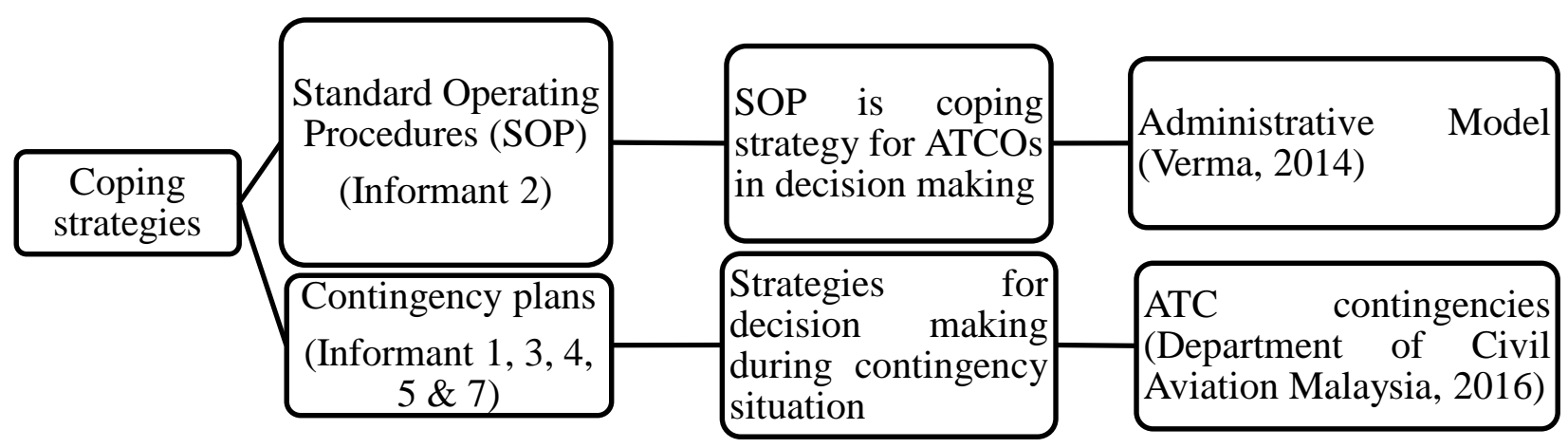

Figure 3. Coping Strategies by ATCOS in Making Decision during Conflict Resolution of Aviation Industry 


\section{IMPLICATIONS, RECOMMENDATIONS, AND CONCLUSIONS}

The implication of this research can be seen towards the unit of analysis involved in decisionmaking during conflict resolution, such as individual, group and organisation. ATCOs became more aware of their roles according to the sector they are responsible for. Besides, this research also influenced policymakers, future researchers, and human resource practitioners in several ways. For example, findings from the study could provide a perspective for the aviation industry when they construct policies related to decision-making among their ATCOs, in the policy. Policymakers may create new policies on related factors ATCOs in decision-making during conflict resolution, collaborative decision-making among ATCOs and coping strategies. Plus, the researchers contributed the knowledge on decision-making among ATCOs to the future researcher. Finally, the practitioners may gain insight on related factors influencing decisions made by ATCOs and coping strategies used by ATCOs in decision-making, specifically during conflict resolution. Therefore, human resource practitioners may get an idea to design appropriate training programs for ATCOs, which will help to enhance their knowledge and skills in decision-making.

The study has provided several recommendations for future researchers, policymakers, human resource practitioners and the aviation industry. Future researchers are highly recommended to conduct related research by applying the quantitative methodology to test any related variables. Using this method can have more participants to be their respondents compared to several informants involved in this research. They are also recommended to conduct research on the comparison of decision making during regular times and in times of crisis. Besides, they can conduct the studies in other CAAM, such as in East Malaysia. Policymakers may create a new policy on related factors considered by ATCOs in the aviation industry. They may also establish a policy on collaborative decision making and a new policy on coping strategies for ATCOs in decision making during conflict resolution. Apart from that, they may consider revisiting the old practices to ensure that the practices are still relevant nowadays. On the other hand, intensive training for ATCOs needs to be proposed by human resource practitioners to enhance their knowledge and skills in decision-making. They can conduct training using Virtual Reality to give more exposure to ATCOs on the actual situation in the aviation industry. In addition, the Department of Civil Aviation Malaysia is recommended to have more collaboration to discuss further on collaborative decision-making. Hence, this will allow all local airports in Malaysia to give ideas and feedback on the decision-making of ATCOs during conflict resolution.

In conclusion, decision-making practices among ATCOs during conflict resolution is influenced by ATCOs types (either they are working as area controllers, approach controllers or aerodrome controllers) and their working experiences. The context of decision-making by ATCOs during conflict resolution in the aviation industry is like the chaotic context in the Cynefin Framework because they need to make a decision quickly. One of the objectives of air traffic services is to prevent collisions between aircraft. Therefore, separation standards and interaction among ATCOs are very crucial for them in decision-making. ATCOs have their own SOPs and contingency plans as their strategies in decision-making which are to be followed strictly. 


\section{ACKNOWLEDGEMENTS}

This research did not receive any specific grant from funding agencies in the public, commercial, or not-for-profit sectors. The authors thank all parties who have been directly or indirectly involved. This work was supported by Civil Aviation Authority Malaysia (CAAM), as they gave permission and provided insights required in the process of inquiry.

\section{REFERENCES}

Akrani, G. (2011). Importance of decision making in management. Retrieved from https://kalyancity.blogspot.com/2011/08/importance-of-decision-making-in.html

Anding, P. N., \& Songan, P. (2000, December). Cognitive modelling as a systematic approach for designing training programs in air traffic control. Paper presented at the 2nd Asia Pacific Conference on Problem-Based Learning, Singapore. Retrieved from https://www.researchgate.net/publication/280544974_Cognitive_Modeling_as_a_Systematic_Ap proach_for_Designing_Training_Programs_in_Air_Traffic_Control

Aygün, D., Yılmaz, İ. G., \& Gülseçen, S. (2017). The value of decision making to the airlines: An Analysis of Passenger Preferences on Check-ins. Journal of Transportation and Logistics, 2(1), 110. doi:10.22532/jtl.299879

Ball, M. O., Chen, C., Hoffman, R., \& Vossen, T. (2000). Collaborative decision making in air traffic management: current and future research directions. Retrieved from https://www.researchgate.net/publication/2365437_Collaborative_Decision_Making_in_Air_Tra ffic_Management_Current_and_Future_Research_Directions

Bonaceto, C., Estes, S., Moertl, P., \& Burns, K. (2005). Naturalistic decision making in the air traffic control tower: Combining approaches to support changes in procedures. Retrieved from https://www.mitre.org/sites/default/files/pdf/05_0663.pdf.

Clark, R. E., Feldon, D. F., Merriënboer, J. J. G. V., Yates, K. A. \& Early, S. (2007). Chapter 43: Cognitive task analysis. Retrieved from https://www.researchgate.net/publication/294699964_Cognitive_task_analysis

Clem (2017). MH17 Three years later: What have we learned? Retrieved from https://www.warontherocks.com/2017/07/mh17-three-years-later-what-have-we-learned/

D’Arcy, J., \& Rocco, P. S. D. (2001). Air traffic control specialist decision making and strategic planning - $\quad$ a $\quad$ field survey. https://pdfs.semanticscholar.org/b5b5/3440dc96641dbd17c9dd6f6575c72dff253a.pdf?_ga=2.213 714769.4526924.1591435685-1838308503.1563721535

Department of Civil Aviation Malaysia. (1999). General rules and procedures. Retrieved from http://aip.dca.gov.my/aip\%20pdf/ENR/ENR\%201/ENR\%201.1/General\%20Rules.pdf 
Department of Civil Aviation Malaysia. (2016). Air traffic inspectorate directive-air traffic services. Retrieved from http://www.caam.gov.my/wp-content/uploads/2015/02/ATID-ATSEd02-eff20161115.pdf

E, X., \& Zhang, J. (2017). Holistic thinking and air traffic controllers' decision making in conflict resolution. Transportation Research Part F: Traffic Psychology and Behaviour, 45,110-121. doi:10.1016/j.trf.2016.11.007

Erzberger, H. (2014). Automated conflict resolution for air traffic control. Retrieved from https://www.researchgate.net/publication/252910210_Automated_conflict_resolution_for_air_tra ffic_control

Hussain, H., \& Lokman, T. (2014, 8 August). Malaysia wants the 'missing' Ukrainian ATC tapes. News Straits Times. Retrieved from https://malaysia.mfa.gov.ua/en/news/2842-publikacija-vmalajzijsykij-gazetithe-new-straits-timesmalaysia-wants-the-missing-ukrainian-atc-tapes

Khakheli, M., \& Morchiladze, G. (2015). Factors affecting decision making in an organisation. International Journal of Management and Commerce Innovations, 3(1), 425-428.

Kudryavtsev, A., \& Pavlodsky. (2012). Description-based and experience-based decisions: individual analysis. Judgment and Decision Making, 7(3), 316-331.

Lewis, R. (2014). In Encyclopaedia Britannica online. Retrieved from https://www.britannica.com/event/Malaysia-Airlines-flight-17

$\mathrm{Li}, \mathrm{W}$. (2011). The casual factors of aviation accidents related to decision errors in the cockpit by system approach. Journal of Aeronautics, Astronautics and Aviation, Series A, 43(3), 159 - 166.

Marume, S. B. M., Ndudzo, D., \& Chikasha, A. S. (2016). Decision-making. International Journal of Business and Management Invention, 5(8), 36-44.

Mishra, L. (2016). Focus group discussion in qualitative research. TechnoLEARN, 6(1), 15.doi:10.5958/2249-5223.2016.00001.2

Neal, A. (2008). The effect of workload on conflict decision making strategies in air traffic control. Retrieved from https://www.researchgate.net/publication/43508853_The_Effect_of_Workload_on_Conflict_Dec ision_Making_Strategies_in_Air_Traffic_Control

Robbins, S. P., \& Coulter, M. (2014). Management (12 ${ }^{\text {th }}$ ed.). England: Pearson Education Limited.

Saunders, M. N. K., Lewis, P., \& Thornhill, A. (2019). Research Methods for Business Students ( $8^{\text {th }}$ ed.). United Kingdom: Pearson Education Limited. 
Sidik, M. F., Rahman, S. M. A., \& Mohamed, W. M. W. (2017). Evaluation of controller strategies in air traffic management for KLFIR oceanic sector. Journal of Mechanical Engineering, 4(5), 121-130.

Snowden, D. J., \& Boone, M. E. (2007). A leader's framework for decision making. Harvard Business School Publishing Incorporation.

Verma, D. (2014). Study and analysis of various decision-making models in an organisation. Journal of Business and Management, 16(2), 171-175.

Yin, R. K. (1994). Case study research: Design and methods, 2d ed. Thousand Oaks, CA: Sage.

Zaraté, P., Konate, J., \& Camilleri, G. (2013, June). Collaborative decision-making tools: A comparative study based on functionalities. Paper presented at the 13th International Conference Group Decision and Negotiation. Stockholm, Sweden. Retrieved from https://core.ac.uk/download/pdf/78384312.pdf 